\title{
Dithering Analysis in an Orthogonal Frequency Division Multiplexing-Radio over Fiber Link
}

\author{
Fakhriy Hario $\mathbf{P}^{1}$, Adhi Susanto ${ }^{2}$, I Wayan Mustika ${ }^{3}$, Sevia M Idrus ${ }^{4}$, Sholeh Hadi $\mathbf{P}^{5}$ \\ ${ }^{1,2,3}$ Department of Electrical Engineering and Information Technology, Gadjah Mada University, Yogyakarta, Indonesia \\ ${ }^{4}$ Department of Communication Engineering, Universiti Teknologi Malaysia, Johor, Malaysia \\ ${ }^{1,5}$ Department of Electrical Engineering, Brawijaya University, Malang, Indonesia
}

\section{Article Info}

Article history:

Received Dec 30, 2015

Revised Feb 25, 2016

Accepted Mar 15, 2016

\section{Keyword:}

BER

Dithering

OFDM

OLP

RoF

SER

\begin{abstract}
Nonlinearity is one major problem broadband communication faced on utilizing the high capacity of optical fibers. That is due to scattering phenomenon, which results in the deviations of wavelengths and energies. The dithering method is applied in the attempt to reduce those scatterings. In this paper, we propose the performance of a dithering technique based new system OFDM-RoF using two modulator scheme and coherent detection to alleviate the characteristics nonlinearity applied on the system. The dithering technique inputs signal externally to the signal processing systems to eliminate the effects of nonlinearity. Here, we report the performance of a dithering technique based on the OFDM-RoF, the results our experiment showed that the applied dithering with 16 QAM modulation can make the system more reliable and increases the power level $1.55 \%$ with 193.1 THz, 2\% with $100 \mathrm{THz}$ and 1.99\% $200 \mathrm{THz}$, the best condition are with $\mathrm{f}_{\mathrm{d}}<\mathrm{f}_{\mathrm{c}}$. However, all condition close proximity in the parameters OLP (optical launch power), BER and SER measurement. The result demonstrated a high efficiency and good power in which the OLP operated 6.396 $\mathrm{dBm} / 4.361 \mathrm{E}-3 \mathrm{~W} \sim \mathrm{fd} 200 \mathrm{THz}, 3.578 \mathrm{dBm} / 2.279 \mathrm{E}-3 \mathrm{~W} \sim \mathrm{fd} 193.1 \mathrm{THz}$ and $6.420 \mathrm{dBm} / 4.3384 \mathrm{E}-3 \mathrm{~W} \sim 100 \mathrm{THz}$. The best BER value is achieved at 0.33 and SER 0.78 at $5 \mathrm{~km} \sim \mathrm{f}_{\mathrm{d}} 100 \mathrm{THz}, 0.33$ and 0.768 for $10 \mathrm{km \sim fd} 193.1 \mathrm{THz}$, 0.478 and 0.92 for $50 \mathrm{~km} \sim \mathrm{fd} 193.1 \mathrm{THz}$.
\end{abstract}

Copyright (C) 2016 Institute of Advanced Engineering and Science. All rights reserved.

\section{Corresponding Author:}

Fakhriy Hario P,

Department of Electrical Engineering, Faculty of Engineering,

Gadjah Mada University,

Jln Grafika No 2, Yogyakarta, 55281, Indonesia.

Email: fakhriy.s3te13@mail.ugm.ac.id

\section{INTRODUCTION}

Radio over Fiber is a process of sending radio signals over optical cables to support faster data delivery. The principle of this technology combines two signals; they are analog signals as a radio and digital signal as a optical source. In this case the signal of optical used CW laser and a signal radio is OFDM; OFDM is one of system communication broadband using high frequency. In this system, be required modulator to combine both of the signal. Radio over Fiber modulates radio signals or superimposed with the light, RF signals were modulated by optical signals, and these signals were transmitted through the optical fiber. Those signals used external modulation to combine and the type used is an external modulator, the one of external modulation is MZM (Mach-Zehnder Modulator), it is used in many analog optical links causes characteristic a high deterministic nonlinearity. Optical modulators (external and direct modulator) used are the main sources of nonlinear distortion in fiber link. Nonlinear effects occur because the frequency shift of the scattered light has a high electric field in the optical fiber, that raises the share of energy absorbed or losses. Response to light any dielectric material will be nonlinear to strong electromagnetic fields. 
Nonlinearity properties of the fiber become very important to be part of scientific studies, nonlinearity on giving evidence of the threshold mechanisms to the amount of data that can be transmitted on a single optical fiber [1]-[2].

In previous research, optimizing of modulator RoF-LTE in nonlinear condition using numerical simulation, modulator used are internal modulator, external modulator and dual electrode modulator. The other paper observed impact of external and internal modulator in RoF system based on frequency dithering to providing high power budget. Compensated nonlinear on RoF also observes in another paper to achieve high power budget using power gain. The other project proposes to investigate performance and characteristic OFDM based on modulation for Rolf [1],[3],[4]. A modeling system to achieve high performance based on OFDM optical network and introduce a novel ICI (Inter Carrier Interference) reduction algorithms cancellation under the various channel environments has already been considered in the literature [5],[6].

This research focuses on dithering technique in new model system to improve optical receiver power and to observe the impact of dither frequency changing in the nonlinear characteristic of optical fiber. This characteristic can degrade the performance and decrease system power.Therefore, the system needs a technique to solve the problem, and the technique is called dithering. Dithering can be a solution to solve nonlinear problems, because one of the characteristics of dithering can be used for affecting the dynamic behavior of a system, in dithering technique, the input externally noise or signal with high and low frequency in signal processing systems to eliminate the effects of nonlinearity, adding amplitude increase the linearity of the system.

In this paper, we propose a novel using dithering technique sine generator source, which will be applied in the new scheme system. In this a novel dithering technique is applied with two modulators on high source frequency of laser, coherent detection. This research will observe the impact of the propose technique by applying some improve dithering frequency technique in fiber, considering nonlinearity characteristics in QAM modulation scheme. The research will use some conditions $f_{d}>f_{c}, f_{d}=f_{c,}, f_{d}<f_{c}, f_{d}$ (freq dither) $f_{c}$ (freq carrier) applied on OFDM-RoF links to show optical performance interconnected with mobile cellular system. Simulation and measurement will use based on license software Optisystem 13.0 and Matlab 2010a.

\section{DITHERING SCHEME METHOD}

Nonlinear characteristic in one system, described nonlinear operator with input output as $y=f_{\mathrm{N}}(x)$, Figure 1 is describe of dithering, wherein the signal $\mathrm{d}(\mathrm{t})$ is the continuous time dithering, $\mathrm{x}(\mathrm{t}) \sim \mathrm{y}(\mathrm{t})$ is the input and output signal of the nonlinear system. The mathematical formula of output system is:

$$
y=h_{1}(t) * f_{\mathrm{N}}(x(t))=h_{1}(t) * f_{\mathrm{N}}\left(r_{g}(t)+d(t)\right)
$$

where $h_{1}(t)$ is the impulse response of the filter $H_{1}(j \omega)$, if already getting a formula of the single-input single-output $f_{\mathrm{wz}}($.$) , output response can be fine to any desired input. [7]-[9].$

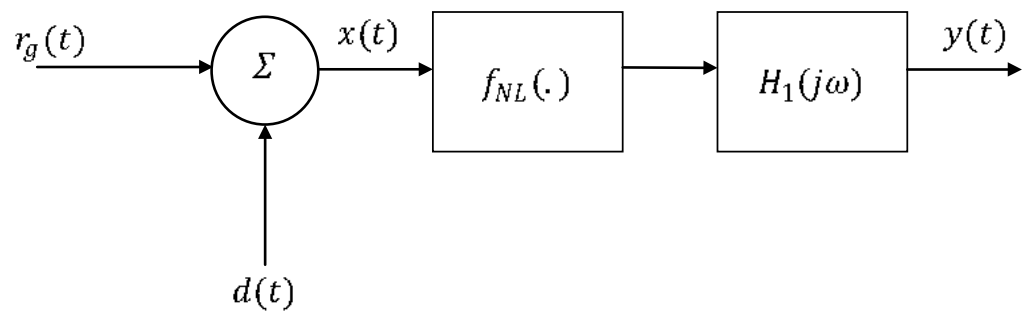

Figure 1. The Nonlinear Single Frequency $f_{d}$ Component after Pass a High Frequency Dithering

The dither signal in high frequency, denoted as $d_{H}(t)$ is expected to have a frequency higher than the maximum frequency component of the input $v_{2}(t)$, usually the fundamental frequency of $d_{M}(t)$ or the minimum frequency component of Fourier transform $D_{H}(\omega)$ is higher than the input signal frequency. The dithering signal $d_{M}(t)$ can be expressed as [9]:

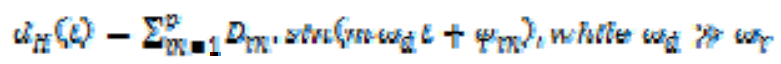

Dithering Analysis in an Orthogonal Frequency Division Multiplexing Radio over.... (Fakhriy Hario P) 


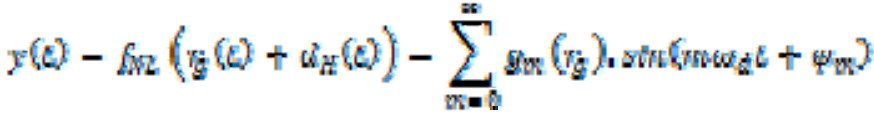

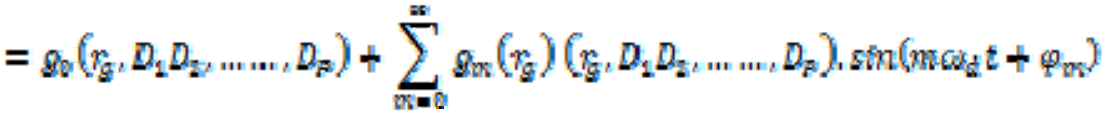

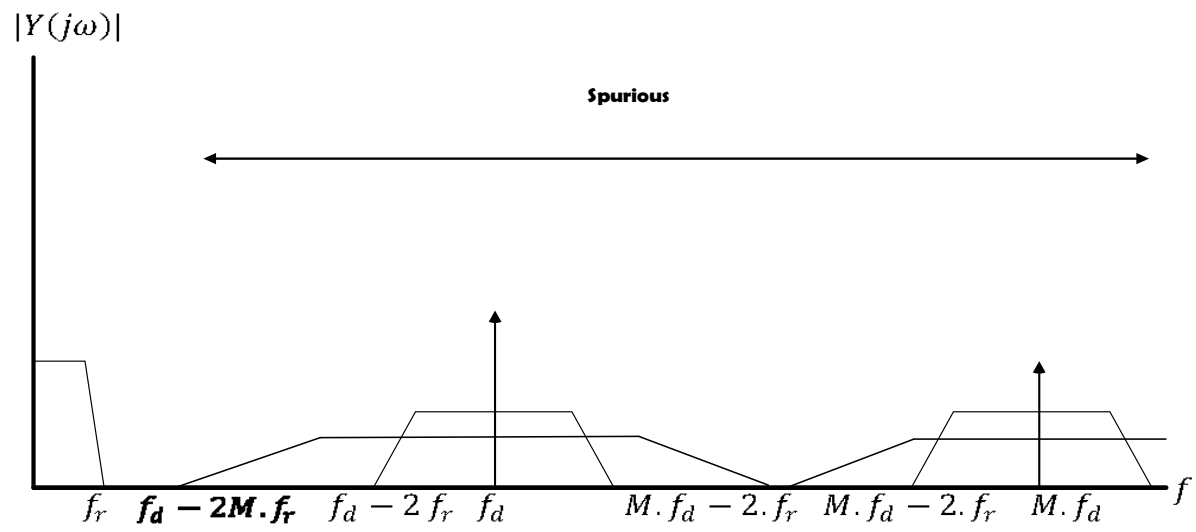

Figure 2. Nonlinear Component after a High Frequency Dithering in Single Frequency $f_{d}$

In the part of radio transmitter, signal baseband on single carrier modulations are composed of 4QAM can be denoted as $\{X(m): m=0,1, \ldots \ldots, N-1\}$, where $m$ is the sub-carrier index and $N$ is the number of sub-carrier, $X(m)$ are then modulated onto orthogonal frequency division multiplexing (OFDM) $S(n)$ given by [10] :

$$
S(n)=\frac{1}{\sqrt{N}} \sum_{m=0}^{N-1} X(m) e^{j 2 \pi m n / N}
$$

Where $n=0,1, \ldots, N-1$ is a time domain index. This system used a component of OFDM OS12, the value of roll off factor $r$ can be arranged from 0 until 1. OFDM modulation results 512 sub-carriers at M-QAM/PSK position (QAM/PSK Mary position) and 1024 points of FFT. The MZM based on EM can be formulated as:

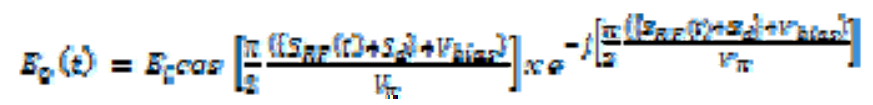

where $E_{0}(t)$ and $E_{\bar{L}}$ are the output and input optical fields modulator, respectively $F_{\text {bias }}$ is biasing voltage, $\nabla_{\pi}$ is half-wave voltage and the $S_{N F}(t)$ power is $2 \mathrm{dBm}$ level for consistency. The equations that describe the behavior of the MZ modulator are:

$$
E_{\text {out }}(t)=E_{\mathrm{m}}(t) \cdot \cos (\theta \theta(t)) \cdot \operatorname{sxp}(v \cdot \Delta \theta(t))
$$

Where $\mathbb{A} \theta$ is the phase difference between two branches and represented as follows:

$$
\Delta \theta(z)=\frac{\pi}{2} \cdot(0.3-E R \cdot(n \pi a d w i a t a n(z)-0.3))
$$

with

$$
E R-1-\frac{4}{\pi} \cdot \operatorname{aratan}\left(\frac{1}{\sqrt{\operatorname{ext} a t}}\right)
$$

and $\Delta \theta$ is the signal phase change defined as: 
$\Delta \theta(t)=S C \cdot \Delta \theta(t) \cdot\left(1+\frac{S}{F}\right)(1-S F)$

Achieving parameter of SC is -1 if negative signal chirp is true and 1 is false, extrat is the extinction ratio, SF is symmetry factor, and modulation (t) is the electrical input signal normalized between 0 and 1 . SMF 28 used in the optical fiber. The characteristics of SMF based on component for effective area and wavelength have imported from OptiFiber 2 Software as shown in the Figure 3.

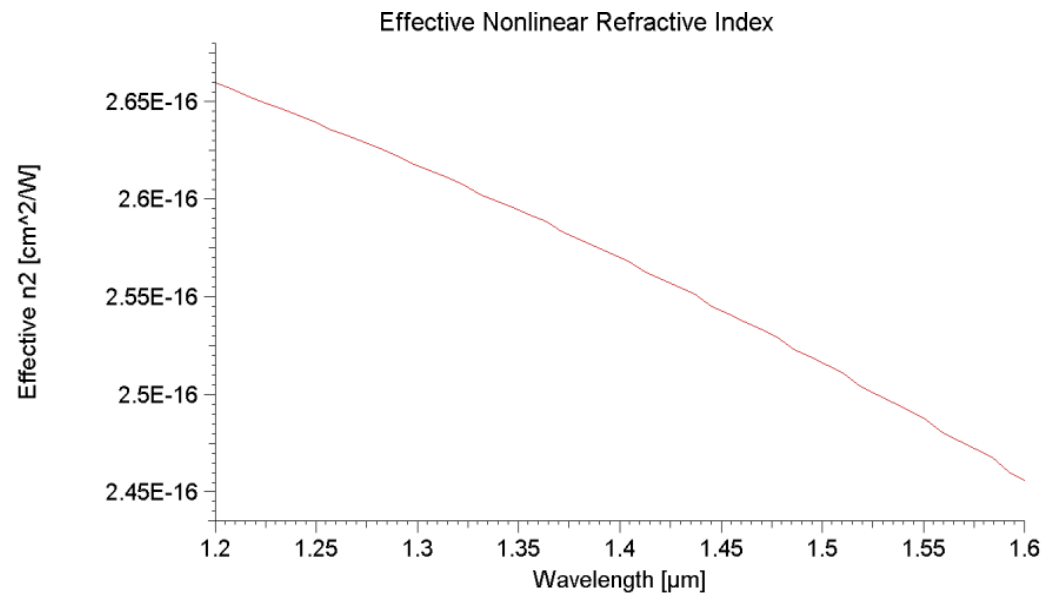

Figure 3. Output of Nonlinear Component for Effective Area and Wavelength

\section{SIMULATION RESULTS AND ANALYSIS}

Analysis of performance system is viewed from the power output every block of the OFDM-RoF system and in the receiver.. The configuration system and output power of each step and block diagram system OFDM-RoF injected dithering concept can be seen in Table 1 and Figure 4.

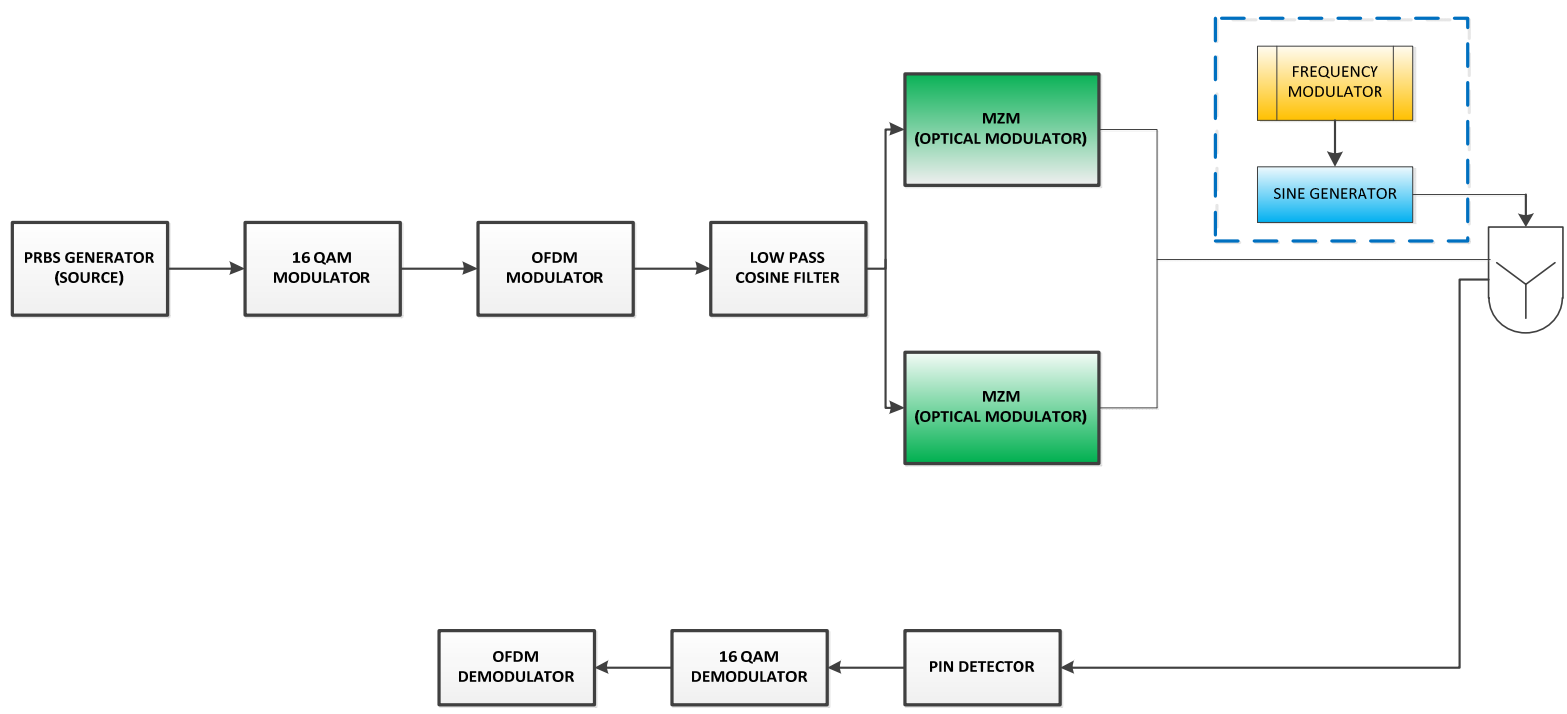

Figure 4. Block Diagram of OFDM-RoF using Dither Scheme 
Tabel 1. Data Simulation

\begin{tabular}{ll}
\hline \multicolumn{1}{c}{ Parameter } & \multicolumn{1}{c}{ Value } \\
\hline Bit Rate & $10 \mathrm{Gbps}$ \\
Modulation Format & $16-\mathrm{QAM}$ \\
Sequence Length & 16384 \\
Sample per Bit & 8 \\
Sample rate & $80 \mathrm{GHz}$ \\
Frequency CW Laser & $193.1 \mathrm{THz}$ \\
CW Laser Power & $9 \mathrm{dBm}$ \\
Extinction Ratio & $60 \mathrm{~dB}$ \\
Switching Bias and RF Voltage & $4 \mathrm{~dB}$ \\
SMF & $5,10,50 \mathrm{~km}$ \\
Attenuation & $0.2 \mathrm{~dB} / \mathrm{km}$ \\
Local Oscillator Power & $-2 \mathrm{dBm}$ \\
Sine Pulse Generator and Pulse Modulator Freq & $50,100,193.1(\mathrm{THz}) \& 100 \mathrm{GHz}$ \\
Linewidth & $10 \mathrm{MHz}$ \\
\hline
\end{tabular}

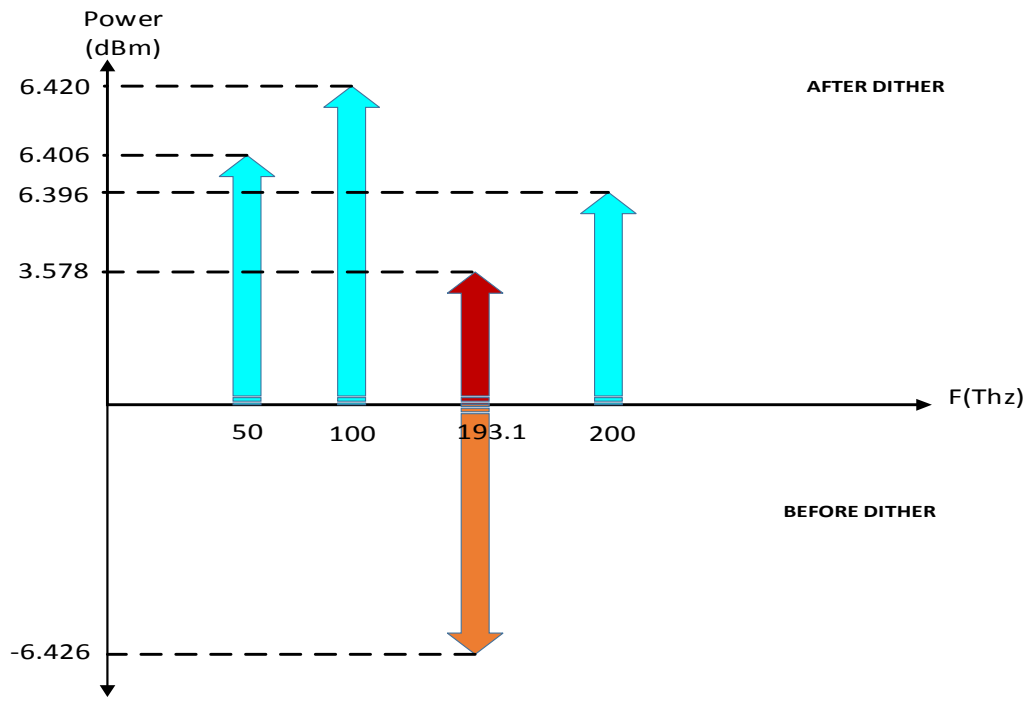

Figure 5. Optical Launch Power before and after Dithering

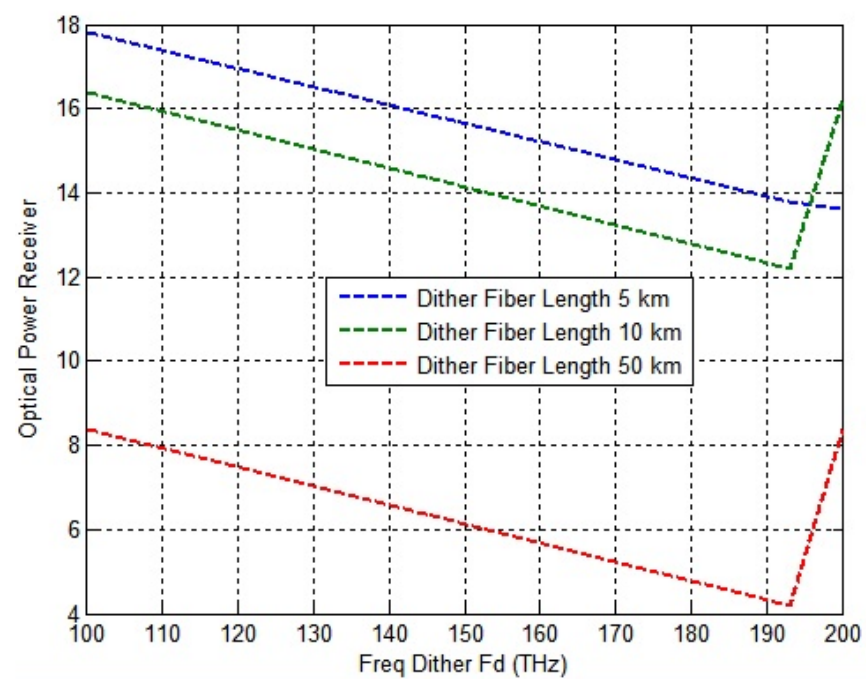

Figure 6. Subsystem Receiver Optical Loop and Fiber Length 
Figure 5 and Figure 6 explains result measurement of Optical Power Meter (OPM) after output of the modulator MZM with constant value $-6.426 \mathrm{dBm}$. High frequency has been applied in this system, the output combines of two modulators will be injected by signal sine generator using user defined pseudorandom as a source signal, after that signal will combine in the modulator MZM. The measurement used dithering results as follows $6.420 \mathrm{dBm}$ at frequency of $100 \mathrm{THz}, 3.578 \mathrm{dBm} \sim 193.1 \mathrm{THz}$ and 6.396 $\mathrm{dBm} \sim 200 \mathrm{THz}$. While used the same frequency $193.1 \mathrm{THz} \mathrm{f}_{\mathrm{d}}=\mathrm{f}_{\mathrm{c}}$ for dithering, the power is not significant to increase then condition $f_{d}>f_{c}, f_{d}<f_{c}$, this condition caused by the interference between frequencies which resulted in the reduction and mutual inter- frequency attenuation, there are some channels are missing. Beside of that, due also dither signal is serving as the accumulator phase values before further quantization of the accumulated result. This dithering of the recurrence around the unmodulated quality results in a more extensive scope of optical frequencies being available along the fiber length.

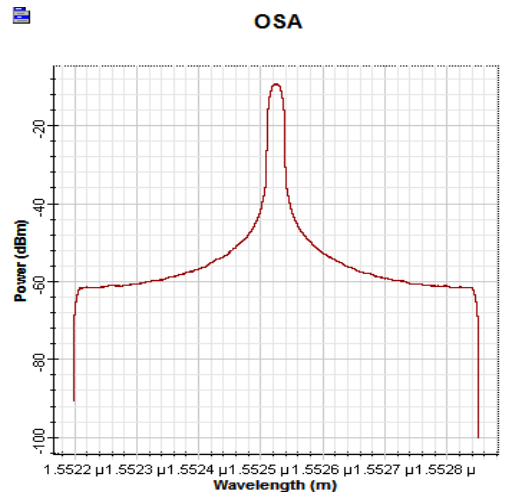

(a)

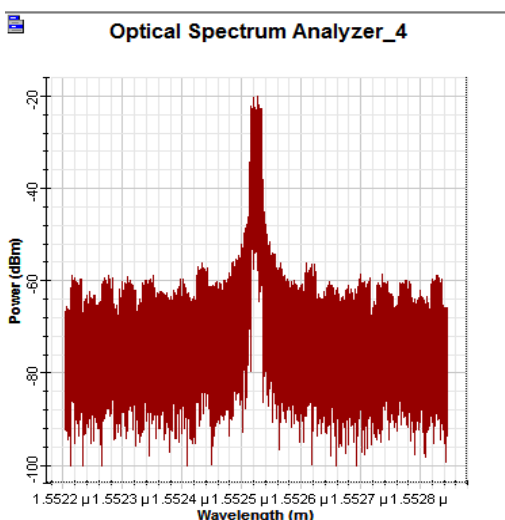

(b)

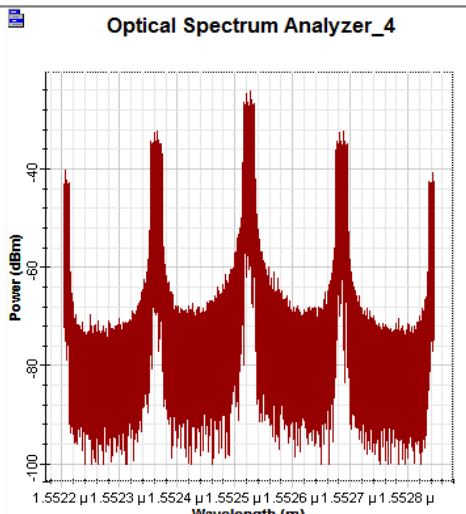

(c)

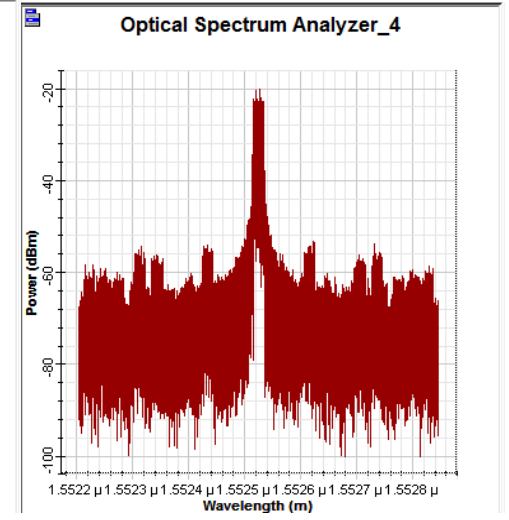

(d)

Figure 7. a) Spectrum before Dithering b) Spectrum after Dithering $F_{d} 100 \mathrm{THz}$ c) Spectrum after Dithering $\left.F_{d} 193.1 \mathrm{THz} d\right)$ Spectrum after Dithering $F_{d} 200 \mathrm{THz}$

Figure 7 shows the condition spectrum after and before dithering for condition condition $\mathrm{f}_{\mathrm{d}}>\mathrm{f}_{\mathrm{c}}, \mathrm{f}_{\mathrm{d}}=$ $f_{c}, f_{d}<f_{c}$, that is showing constant of amplitude dither should be uncorrelated in time, uncorrelated with the analog signal and constant in amplitude. While the condition is an $f_{d}=f_{c}$, there is having a recurrence and overlap, in this way dithering framework can't run superbly when there is no dominant frequency. If $f_{d}>f_{c}$, it will not induce the effect of $f_{d}$ because since the laser is as modulated and chirped by $S_{R F}(t)$. The best achievements for baseband condition is $f_{d}<f_{c}$, for the baseband system [11], condition $\left\{f_{d}>f_{m}\right\}$ is being required as the baseband signal, it will be focused to the direct current. Detail achievements of dithering spectrum after pass on fiber length $5 \mathrm{~km}, 10 \mathrm{~km}$ and $50 \mathrm{~km}$ with $\mathrm{f}_{\mathrm{d}} 100 \mathrm{THz}, 193.1 \mathrm{THz}$ and $200 \mathrm{THz}$ is shown Figure 8 until Figure 10. 


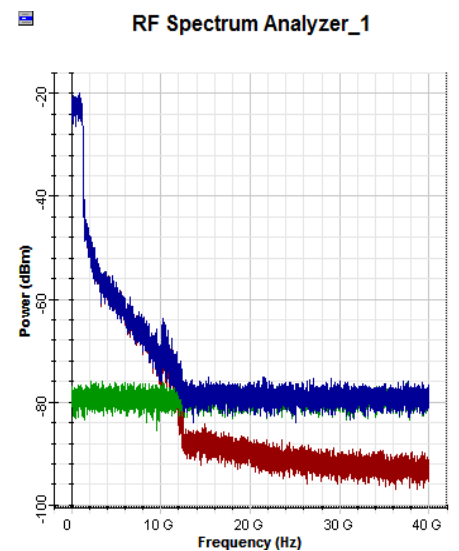

(a)

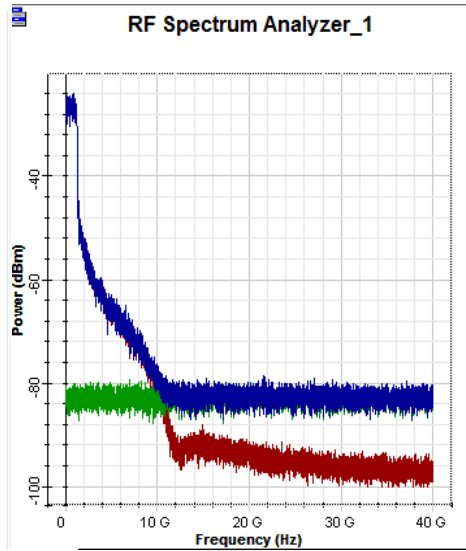

(b)

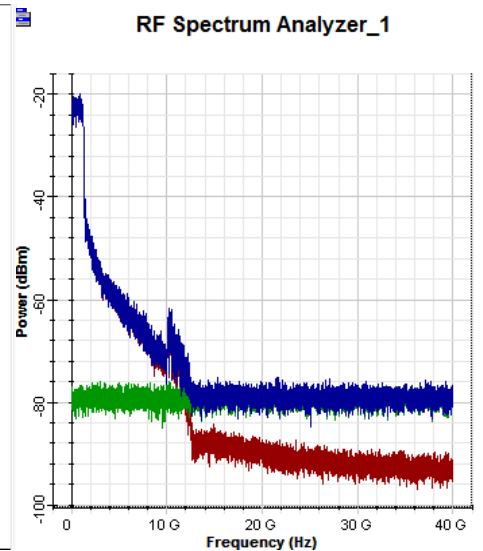

(c)

Figure 8. RF Spectrum in Receiver Fiber 5 km after Dithering a) $F_{d} 100 \mathrm{THz}$ b) F $193.1 \mathrm{THz}$ and c) $\mathrm{F}_{\mathrm{d}} 200$ $\mathrm{THz}$

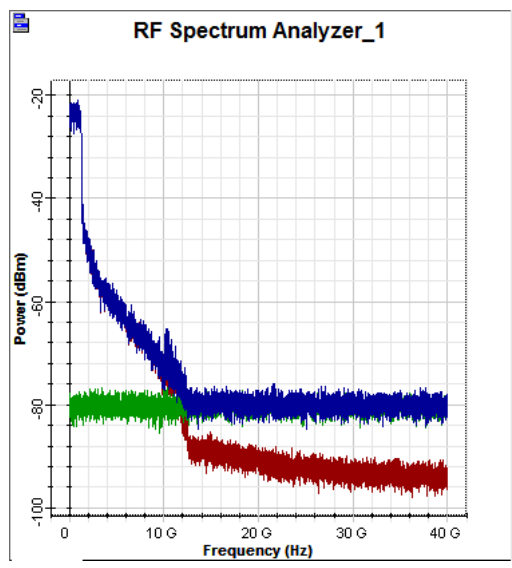

(a)

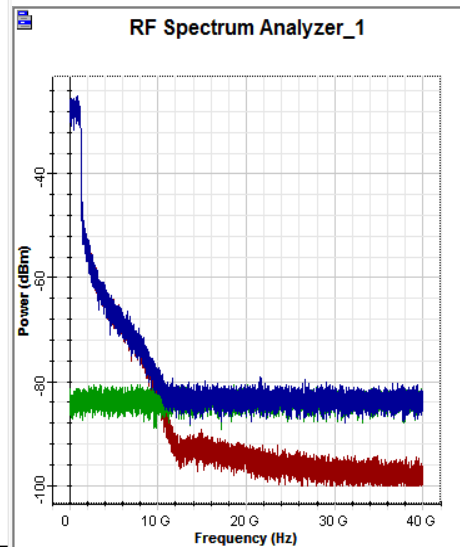

(b)

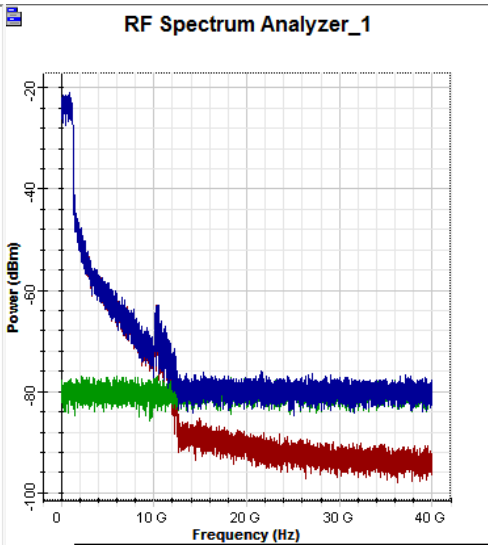

(c)

Figure 9. RF Spectrum in Receiver Fiber 10 km after Dithering a) $F_{d} 100 \mathrm{THz}$ b) $F_{d} 193.1 \mathrm{THz}$ and c) $F_{d} 200$ $\mathrm{THz}$

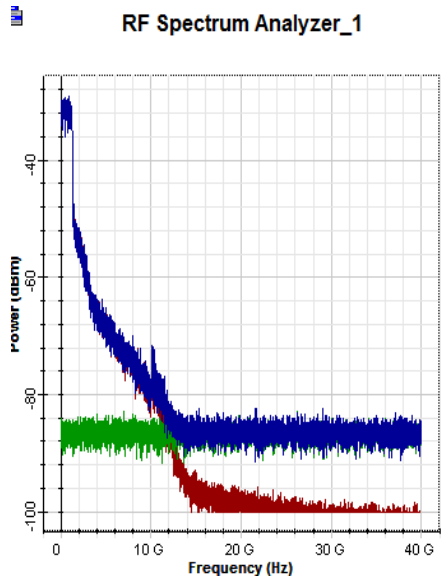

(a)

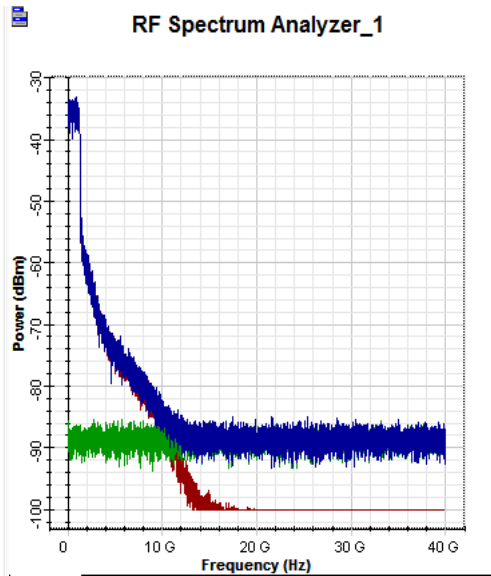

(b)

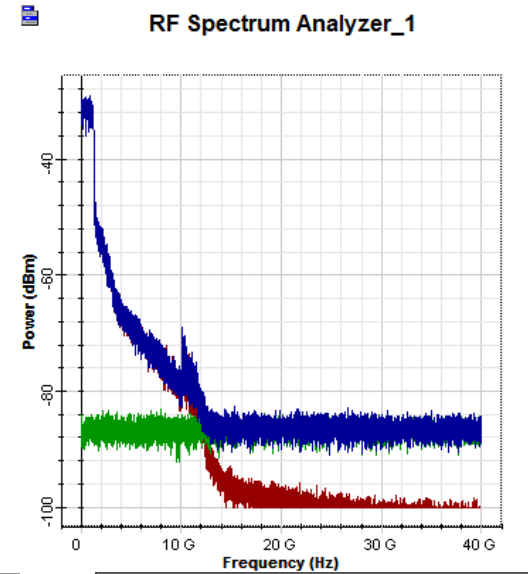

(c)

Figure 10. RF Spectrum in Receiver Fiber 50 km after Dithering a) $F_{d} 100 \mathrm{THz}$ b) $F_{d} 193.1 \mathrm{THz}$ and c) $F_{d}$ $200 \mathrm{THz}$ 


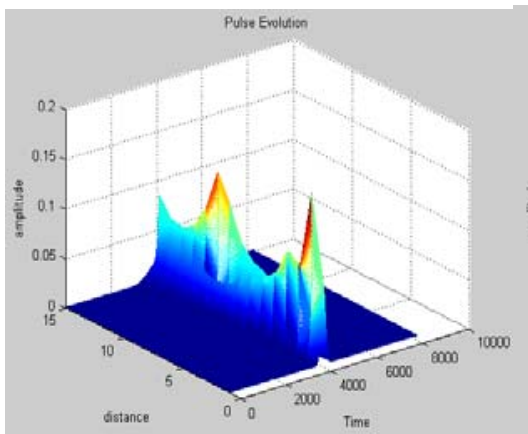

(a)

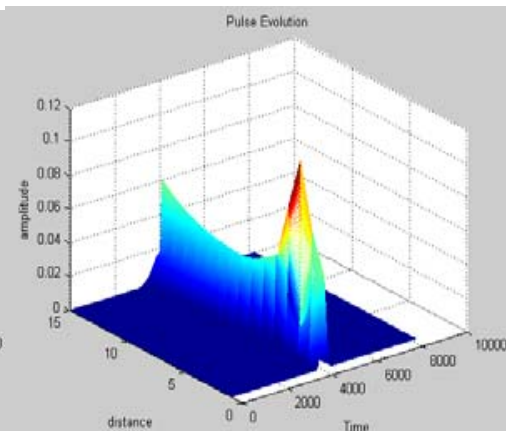

(b)

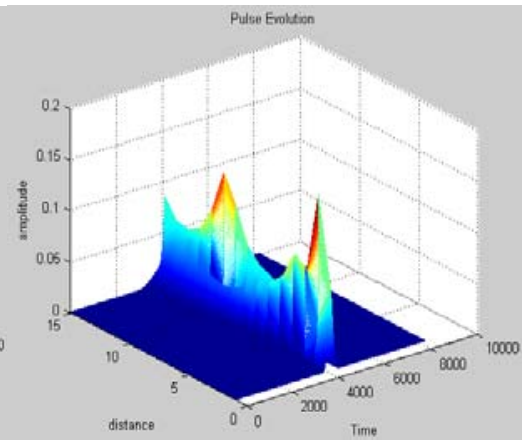

(c)

Figure 11. Nonlinear Impact after using Frequency Dithering

Based on output of optical spectrum analyzer that was generated before the optical signal through single mode fiber, at the carrier of $193.1 \mathrm{GHz}$ and frequency dithering $100 \mathrm{GHz}$ shows the power is approximately $17.371 \mathrm{dBm}$ at $5 \mathrm{~km}, 16.371 \mathrm{dBm} \sim 10 \mathrm{~km}$ and $8.371 \mathrm{dBm} \sim 50 \mathrm{~km}$, used $193.1 \mathrm{THz}$ shows power $13.399 \mathrm{dBm} \sim 5 \mathrm{~km}, 12.356 \mathrm{dBm} \sim 10 \mathrm{~km}, 4.33 \mathrm{dBm} \sim 50 \mathrm{~km}$, the last power of approximately $13.320 \mathrm{dBm} \sim 5 \mathrm{~km}, 16.371 \mathrm{dBm} \sim 10 \mathrm{~km}$ and $8.371 \mathrm{dBm} \sim 50 \mathrm{~km}$ for $\mathrm{f}_{\mathrm{d}} 200 \mathrm{THz}$ BER and SER result 0.33 and $0.78 \mathrm{f}_{\mathrm{d}} 100 \mathrm{THz}$ and fiber length $5 \mathrm{~km}, 0.36$ and 0.84 fiber length $10 \mathrm{~km}$ and 0.54 and 0.94 fiber length $50 \mathrm{~km}$. The other fiber length and $\mathrm{f}_{\mathrm{d}} 193.1 \mathrm{THz}$ we get BER and SER 0.35 and $0.82 \sim 5 \mathrm{~km}, 0.33$ and $0.768 \sim$ $10 \mathrm{~km}, 0.478$ and $0.92 \sim 50 \mathrm{~km} . \mathrm{f}_{\mathrm{d}} 200 \mathrm{THz}$ BER and SER get value 0.35 and $0.82 \sim 5 \mathrm{~km}, 0.43$ and $0.884 \sim$ $10 \mathrm{~km}, 0.52$ and $0.93 \sim 50 \mathrm{~km}$.

Figure 11 shows the impact of nonlinear fiber propagation after using a dither technique that to calculate of nonlinearity impact using numerical method Split-Step Fourier Method (SSFM) with nonlinearity factor (gamma) is $0.003 \mathrm{~W} / \mathrm{m}$, dither frequency used are (a) $100 \mathrm{THz}$, (b) $193.1 \mathrm{THz}$, (c) 200 $\mathrm{THz}$, each the power of value is $4.384 \mathrm{E}-3 \mathrm{~W}, 2.279 \mathrm{E}-3 \mathrm{~W}, 4.361 \mathrm{E}-3 \mathrm{~W}$. The best power in $5 \mathrm{~km}$ is 17.371 $\mathrm{dBm}, 16.371 \mathrm{dBm} \sim 10 \mathrm{~km}$ and $8.371 \mathrm{dBm} \sim 50 \mathrm{~km}$, operated on $\mathrm{f}_{\mathrm{d}}=100 \mathrm{THz}$. In the other scheme without dithering technique, in $193.1 \mathrm{THz}$ the power approximately $5 \mathrm{~km} \sim 1.43 \mathrm{E}-3 \mathrm{~W}, 10 \mathrm{~km} \sim 1.12 \mathrm{E}-3 \mathrm{~W}$ and 50 km 191.127 E-6 W.

However, frequency dithering could increase the performance of the system, the results of the simulation after applied dither technique showed a consistency of condition $f_{d}<f_{c}$ is the best condition to produce better power, the amount of value $f_{d}$ is influenced to the value of output power.

\section{CONCLUSION}

In this paper, dither methods were has shown mitigation result of the nonlinear effect in the system. We discovered this method can increase OLP if condition is achieved $\mathrm{f}_{\mathrm{d}}<\mathrm{f}_{\mathrm{c}}$. However, all conditions reach a high efficiency and good power, in which the OLP operated $6.396 \mathrm{dBm} / 4.361 \mathrm{E}-3 \mathrm{~W} \sim \mathrm{f}_{\mathrm{d}} 200 \mathrm{THz}, 3.578$ $\mathrm{dBm} / 2.279 \mathrm{E}-3 \mathrm{~W} \sim \mathrm{f}_{\mathrm{d}} 193.1 \mathrm{THz}$ and $6.420 \mathrm{dBm} / 4.3384 \mathrm{E}-3 \mathrm{~W} \sim 100 \mathrm{THz}$. The best BER achieved in 0.33 and SER 0.78 at $5 \mathrm{~km} \sim \mathrm{f}_{d} 100 \mathrm{THz}, 0.33$ and 0.768 for $10 \mathrm{~km} \sim \mathrm{f}_{\mathrm{d}} 193.1 \mathrm{THz}, 0.478$ and 0.92 for $50 \mathrm{~km} \sim \mathrm{f}_{\mathrm{d}}$ $193.1 \mathrm{THz}$, this resulting that the system increased 1.55\% 193.1 THz, 2\% 100 THz, 1.99\% $200 \mathrm{THz}$ of it's performance. The signal produces an optical signal with fewer harmonic in the sidebands, which the condition occurs because there are similarities of frequency dithering and frequency carrier of the signal. Applying of dithering method in the system can reduce nonlinear characteristics, thus the OFDM-RoF system at 16-QAM modulation with dithering is better than without dithering system.

\section{REFERENCES}

[1] T. Kanesan, et al., "Optimization of Optical Modulator for LTE RoF in Nonlinear Fiber Propagation,” IEEE Photonics Technology Letters, vol/issue: 24(7), 2012.

[2] D. S. P. Karthikeyan, “OFDM Signal Improvement Using Radio over Fiber for Wireless System,” IJCNWC, vol. 3, pp. 287-291, 2013.

[3] T. Kanesan, et al., "Investigation of Optical Modulators in Optimized Nonlinear Compensated LTE RoF System," IEEE Journal of Lightwave Technology, vol/issue: 32(10), 2014.

[4] T. Kanesan, et al., "Optimization of Optical Modulator for LTE RoF in Nonlinear Fiber Propagation," IEEE Journal of Lightwave Technology , vol/issue: 24(7), pp. 617-619, 2012. 
[5] B. U. Rindhe, et al., "Implementation of Optical OFDM Based System for Optical Networks", IJECE (International Journal of Electrical and Computer Engineering), vol/issue: 4(5), 2014.

[6] A. H. Sharief, et al., "An Improved ICI Self Cancellation Scheme for OFDM Systems Under Various Channels," IJECE (International Journal of Electrical and Computer Engineering), vol/issue: 6(2), 2016.

[7] Y. Wong, et al., "Performance Analysis of the OFDM Scheme for Wireless over Fiber Communication Link," IJCTE, vol/issue: 4(5), pp. 807-811, 2012.

[8] S. Mahajan and N. Kumar, "Performance Analysis of Coded OFDM Signal for Radio over Fiber Transmission," IOSRJEEE, vol/issue: 1(1), pp. 49-52, 2012.

[9] R. Karthikeyan and S. Prakasam, "A Review - OFDM-RoF (Radio over Fiber) System for Wireless Network,” IJRCCT, vol/issue: 3(3), pp. 344-349, 2014.

[10] A. A. Gurphh Sin, “OFDM Modulation Study for a Radio-over-Fiber System for Wireless LAN (IEEE 802.11a)," ICICS-PCM IEEE, pp. 1460-1464, 2003.

[11] C. Koebele, et al., "Nonlinear Effects in Mode-Division-Multiplexed Transmission Over Few-Mode Optical Fiber," IEEE Photonics Technology Letter,” vol/issue: 23(18), pp. 1316-1318, 2011.

\section{BIOGRAPHIES OF AUTHORS}
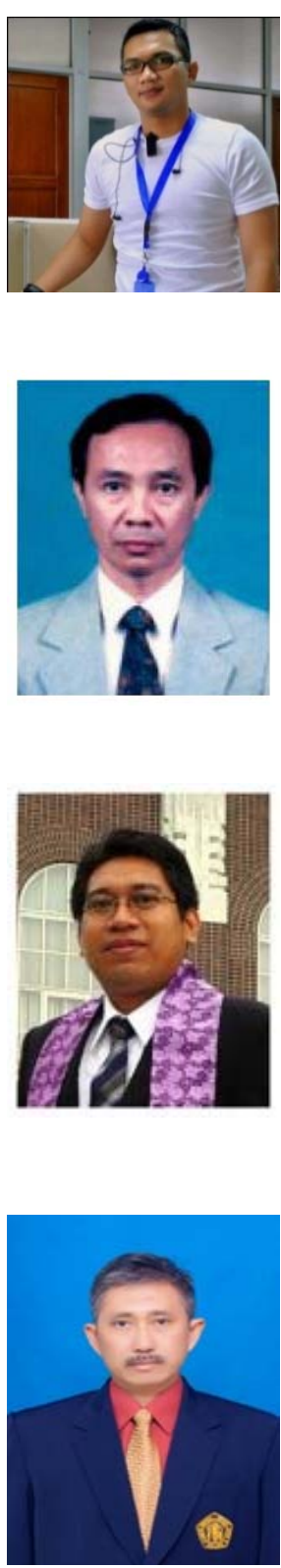

Fakhriy Hario P was born in 1984. He received the Bachelor degree in 2008 and M.Eng degree in 2010 from Brawijaya University, Indonesia. Currently, He is Ph.D candidate at Gadjah Mada University. He was a student member of the IEEE Indonesia Section in 2014. His current research is focused and develops in Nonlinearity Fiber, Radio over Fiber, OFDM, Raman Scattering, and Mobile Communication Model using Monte Carlo method.

Prof (Emeritus) Adhi Susanto. He received B.Sc Physic in 1964 Gadjah Mada University, Indonesia, and the M.Sc degree in electrical engineering in 1966 from University of California, Davis, USA and the Ph.D. degree also electrical engineering at University of California, Davis, USA in 1986. He is Prof (Emeretus) in Gadjah Mada University. Research areas Electronics Engineering, Image Processing, Signal Processing, Adaptive System, Classification and Pattern Recognition Techniques.

I Wayan Mustika., Ph.D. He received the B.Eng. degree in electrical engineering from Gadjah Mada University, Indonesia, in 2005, and the M.Eng. degree in computer engineering from King Mongkut's Institute of Technology Ladkrabang (KMITL), Thailand, in 2008, and the Ph.D. degree in informatics from Kyoto University, Japan, in 2011. He is currently a Lecturer at Gadjah Mada University. He was a Student Activities Advisor of IEEE Indonesia Section in 2014 and he is currently a Secretary of IEEE Indonesia Section. His research interests include smart systems, machine-to-machine communications, and resource management in cognitive radio and heterogeneous networks with a particular emphasis on spectrum sharing and game theory. He received the Young Researcher's Encouragement Award from IEEE VTS Japan in 2010 and Student Paper Award from IEEE Kansai Section in 2011. He is a member of the IEEE.

Dr. Sholeh Hadi P is the Deputy Dean of the faculty engineering Brawijaya University. He received the B.Eng. degree in electrical engineering from Brawijaya University, Indonesia, and the M.Sc degree in electrical engineering from University of Indonesia, and the Ph.D. degree also electrical engineering in University of Indonesia. He is currently a Lecturer at Brawijaya University and colloborotion project with the Indonesian Institute of Science on fiber optic major. Research areas Electronics Engineering, Optical Fiber, Signal Processing, Antenna and Telecommunication. 


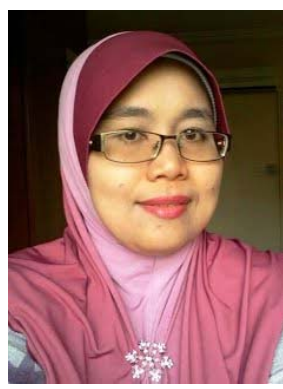

Dr Sevia M. Idrus is the Deputy Director Innovation of the UTM Innovation and Commercialisation Centre and faculty member of the Faculty of Electrical Engineering and Infocomm Research Alliance, UTM. She received her Bachelor in Electrical Engineering in 1998 and Master in Engineering Management in 1999, both from UTM. She obtained her Ph.D in 2004 from the University of Warwick, United Kingdom in optical communication engineering. She has served UTM since 1998 as an academic and administrative staff. Her main research interests are optical communication system and network, optoelectronic design, and engineering management. Her research output has been translated into a number of publications and IPR including a high-end reference books, 'Optical Wireless Communication: IR Connectivity' published by Taylor and Francis, 49 book chapters and monographs, over 150 technical papers, 2 patents granted, 35 patent filings and holds 28 UTM copyrights. 